\title{
Qualidade de abóbora minimamente processada armazenada em atmosfera modificada ativa
}

\section{Quality of fresh-cut squash stored in active modified atmosphere}

\author{
Viviane Citadini Russo; Érica Regina Daiuto²*; Bruna Lourenço Santos³ Mariana \\ Gonçalves Lozano ${ }^{4}$; Rogério Lopes Vieites ${ }^{5}$; Marcos Ribeiro da Silva Vieira ${ }^{6}$
}

\section{Resumo}

Avaliou-se o efeito da atmosfera modificada ativa na qualidade de abóbora minimamente processada (MP). Os pedaços de abóbora foram acondicionados em embalagens plásticas e submetidos a aplicação de gases nas seguintes concentrações: $0,03 \% \mathrm{CO}_{2}$ e $21 \% \mathrm{O}_{2}$ (controle $\mathrm{T} 1$ ); $5 \% \mathrm{CO}_{2}$ e $4 \% \mathrm{O}_{2}$ (T2); $6 \% \mathrm{CO}_{2}$ e $4 \% \mathrm{O}_{2}$ (T3); $7 \% \mathrm{CO}_{2}$ e $4 \% \mathrm{O}_{2}$ (T4); $8 \% \mathrm{CO}_{2}$ e 4\% $\mathrm{O}_{2}$ (T5). No T6 foi feita aplicação de vácuo na embalagem. As embalagens contendo as abóboras MP foram armazenadas à temperatura de $5{ }^{\circ} \mathrm{C}$ e umidade relativa de $75 \%$ durante 12 dias. As análises realizadas foram perda de massa, acidez total (AT), pH, sólidos solúveis (SS), ratio, firmeza, cor, atividade antioxidante por DPPH e teor de carotenóides. A perda de massa foi gradual e baixa até o nono dia de armazenamento. Os valores de AT aumentaram ao longo do período experimental sendo superior para os T1 e T2. O aumento de SS durante o armazenamento das abóboras MP foi menor para os T3 e T4. A luminosidade se manteve durante o armazenamento sendo superior para o T5. Os componentes de cor vermelho e amarelo diminuíram ao longo do período experimental. A atividade antioxidante e teores de carotenóides diminuíram após o nono dia de armazenamento. A abóbora MP manteve sua qualidade até o $9^{\circ}$ dia de armazenamento, com superioridade para os tratamentos T3 e T4 no que se refere aos valores de perda de massa, AT e teores de carotenóides.

Palavras-chave: Curcubita máxima Duchesne, atividade antioxidante, carotenóides

\begin{abstract}
The active modified atmosphere effect was evaluated in the quality of squash fresh-cut (MP).. The squash pieces were conditioned in plastic packings and submitted the gases application in the following concentrations: $0.03 \% \mathrm{CO}_{2}$ and $21 \% \mathrm{O}_{2}$ (controls $\mathrm{T} 1$ ); $5 \% \mathrm{CO}_{2}$ and $4 \% \mathrm{O}_{2}$ (T2); $6 \% \mathrm{CO}_{2}$ and $4 \%$ $\mathrm{O}_{2}$ (T3); $7 \% \mathrm{CO}_{2}$ and $4 \% \mathrm{O}_{2}$ (T4); $8 \% \mathrm{CO}_{2}$ and $4 \% \mathrm{O}_{2}$ (T5). In $\mathrm{T} 6$ it was made vacuum application in the packing. The packings containing the squash were stored in to the temperature of $10{ }^{\circ} \mathrm{C}$ and relative humidity of $75 \%$ for 12 days. The evaluated analyses were weigth loss, total acidity (AT), $\mathrm{pH}$, soluble solids (SS), ratio, firmness, color, antioxidant activity for DPPH and carotenoids content. The weigth loss was gradual and low until the ninth day of storage. The values of AT increased along the experimental period being superior for T1 and T2. The increase of SS during the storage of the freshcut squash went smaller for T3 and T4. The brightness stayed during the storage being superior for T5, already the color components red and yellow decreased along the experimental period. The antioxidant
\end{abstract}

\footnotetext{
1 Doutoranda no curso Energia na Agricultura da Faculdade de Ciências Agronômicas, FCA, Universidade Estadual Paulista "Júlio de Mesquita Filho" UNESP, Botucatu, SP. E-mail: vivianecitadini@hotmail.com

2 Pós doutoranda no curso de Horticultura da FCA/UNESP, Botucatu, SP. E-mail: erdaiuto@uol.com.br

3 Discente de Graduação no Curso de Engenharia Agronômica da FCA/UNESP, Botucatu, SP. E-mail: blsantos@fca.unesp.br

4 Discente do Curso de Nutrição do Instituto de Biociências, UNESP, Botucatu, SP. E-mail: chalaza.lozano@hotmail.com

5 Prof. Titular do Departamento de Gestão e Tecnologia Agroindustrial da FCA/UNESP. Botucatu, SP. E-mail: vieites@fca.unesp.br

6 Doutorando na FCA/UNESP, Botucatu, SP. E-mail: m.r.s.v@hotmail.com

Autor para correspondência
} 
activity and carotenoids content decreased with the storage. Fresh-cut squash maintained her quality up to the $9^{\text {th }}$ of storage, with superiority for the treatments $\mathrm{T} 3$ and T4, in what refers to the weigth loss, AT values and carotenoids content.

Key words: Curcubita máxima Duchesne, antioxidant activity, carotenoids

\section{Introdução}

As mudanças ocorridas nos setores econômico, social e tecnológico requerem do mercado maior oferta por produtos alimentícios ditos de conveniência. Neste contexto, justifica-se o aumento do consumo de frutas e hortaliças, seja in natura, pré-processado ou processado, pela riqueza nutricional. O processamento mínimo de frutas e hortaliças é uma tendência de mercado, e que atualmente, se encontra em franca expansão. Os produtos que passam por esse tipo de processo tornam-se convenientes pela redução do tempo de preparo, melhor padronização e redução de perdas pós-colheita.

A fisiologia dos produtos hortícolas minimante processados (MP) é, essencialmente, a fisiologia de tecidos vegetais intactos que sofreram injúrias (KLUGE et al., 2006). No entanto, hortaliças e frutos MP são mais perecíveis do que quando intactos, porque são submetidos a severo estresse físico advindo principalmente do descascamento e corte. O efeito do corte leva a um aumento da taxa respiratória e produção de etileno, com aumento da atividade enzimática devido à ruptura de muitas células (DURIGAN; CASSARO, 2000; CHITARRA; CHITARRA, 2005). Quanto maior a gravidade da injúria nos tecidos, maior é a velocidade de deterioração dos produtos MP. Assim, é de se esperar que diferentes tipos de corte promovam diferentes respostas quanto à qualidade dos produtos minimamente processados (BRECHT, 1995).

A abóbora contém (em $1 \mathrm{~kg}$ ) 1,3\% de fibras e $96 \%$ de água, com a seguinte composição: 40 calorias, $280 \mathrm{mg}$ de vitamina A, $700 \mathrm{mg}$ de vitamina B5, $100 \mathrm{mg}$ de vitamina B2, $55 \mathrm{mg}$ de vitamina B, além de sais como cálcio, fósforo, potássio, sódio, ferro e enxofre (LUENGO et al., 2000).
A hortaliça apresenta ainda carotenóides que são pigmentos lipossolúveis com coloração que varia do amarelo ao vermelho, presentes em frutas e outros vegetais. Dentre algumas fontes de vegetais de carotenóides pode-se citar além da abóbora, o pimentão vermelho e amarelo, cará azeitona roxa, repolho roxo, folhas verdes escuras (como brócolis e espinafre), alface, aipo, maçã, damasco, manga, ameixa, frutas vermelhas, melancia, laranja, tangerina, nectarina e mamão (SILVA et al., 2010). Os carotenóides, precursores da vitamina A, o $\beta$-caroteno e seus derivados possuem um extenso sistema de ligações duplas conjugada. Este sistema extenso é uma das características estruturais dos carotenóides responsáveis pelas propriedades antioxidantes atribuídas (GERMAN; DILLARD, 1998). A função antioxidante dos carotenóides desempenha um papel importante na redução do risco de câncer de próstata, catarata, arteriosclerose e no processo de envelhecimento (DAMODARAN; PARKIN; FENNEMA, 2008). Os antioxidantes complexam os radicais livres e inibem a cadeia de iniciação ou interrompem a cadeia de propagação das reações oxidativas pelos radicais (PODSEDEK, 2007).

As abóboras podem ser consumidas verdes ou amadurecidas. As verdes são preparadas em pratos salgados e as maduras são utilizadas, geralmente, na elaboração de doces caseiros ou industrializados e também em diversos pratos salgados (CAMARGO FILHO; MAZZEI; ALVES, 2003). De alto valor nutritivo, o consumo de abóbora não é maior devido ao grande tamanho dos frutos e a dificuldade no descascamento, tornando seu preparo trabalhoso. Por isso, assim como já relatado por Sasaki et al. (2006) e aliado ao valor nutricional, a oferta deste produto na forma minimamente processada é uma alternativa interessante para o mercado. 
A abóbora madura apresenta alguns problemas tecnológicos assim como a beterraba, conforme já mencionados por Kluge et al. (2006), como a descoloração superficial, dano semelhante ao que ocorre em cenoura minimamente processada, denominado "white blush" (BARRY-RYAN; O'BERIRNE, 2000). Silva et al. (2009) também aponta em abóbora minimamente processada, os sintomas mais comuns da injúria pelo frio, como o escurecimento e o afundamento de pequenas áreas da polpa.

O uso filmes plásticos flexíveis, que agem como embalagem de atmosfera modificada pode aumentar a vida útil de vegetais. Esta técnica utilizada como um suplemento da refrigeração promove o abaixamento da taxa de respiração pelo aumento do nível de $\mathrm{CO} 2$ e decréscimo do nível de $\mathrm{O}_{2}$ (RAI et al., 2002) além disso, minimiza a perda de água (CISNERO - ZEVALLOS; KROCHTA, 2002).

O objetivo da pesquisa é avaliar o efeito da atmosfera modificada ativa na qualidade de abóbora minimamente processada.

\section{Material e Métodos}

A Abóbora Paulista madura (Curcubita máxima Duchesne) foi obtida no mercado local (varejo) do município de Botucatu - SP. A hortaliça foi selecionada, lavada em água corrente e detergente neutro para remover resíduos da colheita e microrganismos aderidos á superfície dos frutos, e imersos em solução de hipoclorito de sódio a 200 ppm por 20 minutos. As abóboras foram descascadas e cortadas em cubos de $3 \mathrm{~cm}$ de aresta, sendo imersos, após o corte, em solução de hipoclorito de sódio a 100 ppm por 10 minutos, drenadas em escorredor doméstico, acondicionados em embalagens de plásticas de nylon+polietileno e submetidos a aplicação de gases nas seguintes concentrações: 0,03\% $\mathrm{CO}_{2}$ e $21 \% \mathrm{O}_{2}$ (controle - Tratamento 1- T1); $5 \% \mathrm{CO}_{2}$ e $4 \% \mathrm{O}_{2}$ (Tratamento 2 - T2); $6 \% \mathrm{CO}_{2}$ e $4 \%$ $\mathrm{O}_{2}$ ( tratamento 3- T3); 7\% $\mathrm{CO}_{2}$ e 4\% $\mathrm{O}_{2}$ (tratamento 4- T4); $8 \% \mathrm{CO}_{2}$ e $4 \% \mathrm{O}_{2}$ (tratamento 5- T5). No tratamento 6 (T6) foi feita aplicação de vácuo na embalagem. Para abóbora MP não existem estudos na literatura sobre a concentração mais adequada de gases, portando a escolha foi feita considerando-se estudos em outras hortaliças.As embalagens foram armazenadas em câmara climatizada à temperatura de $5{ }^{\circ} \mathrm{C}$ e umidade relativa de $75 \%$. Cada tratamento constou de 3 repetições e as análises foram realizadas em triplicata. As amostras foram avaliadas a cada 3 dias durante 12 dias e as análises realizadas foram: perda de massa, teor de sólidos solúveis (SS), acidez (AT), relação SS/acidez (ratio), pH, firmeza (textura), coloração, atividade antioxidante medida através da desativação do radical $\mathrm{DPPH}$ - e teor de carotenóides totais.

A perda de massa fresca foi obtida pela pesagem das embalagens em balança analítica, considerando a massa inicial de cada amostra, com os resultados expressos em percentagem.

O teor de sólidos solúveis (SS) foi realizado através de leitura refratométrica direta em graus Brix (Brix), em três amostras, com o refratômetro tipo Abbe, marca ATAGO - N1, de acordo com os procedimentos descritos por Tressler e Joslyn (1961).

A acidez total (AT) foi expressa em gramas de ácido málico por 100 gramas de polpa (g de ácido málico $100 \mathrm{~g}^{-1}$ ), determinado em três amostras da titulação de 10 gramas de polpa homogeneizada e diluída para $100 \mathrm{~mL}$ de água destilada, com solução padronizada de hidróxido de sódio a 0.1 $\mathrm{N}$, tendo como indicador do ponto de viragem a fenolftaleína, conforme metodologia recomendada pelo Instituto Adolfo Lutz (2008). Os resultados foram expressos em g de ácido málico $100 \mathrm{~g}^{-1} \mathrm{da}$ amostra. $\mathrm{O}$ índice de maturação ratio foi estimado pela relação entre o teor de sólidos solúveis e acidez titulável (TRESSLER; JOSYLYN, 1961).

O potencial hidrogêniônico $(\mathrm{pH})$ foi determinado na polpa triturada da abóbora utilizando-se um potenciômetro (Digital DMPH-2), segundo a técnica descrita por Official Methods of Analysis 
of the Association of Official Analytical ChemistryAOAC (1992).

A firmeza foi determinada em texturômetro (STEVENS - LFRA texture analyser) com a distância de penetração de $10 \mathrm{~mm}$ e velocidade de 2,0 mm seg-1, utilizando-se o ponteiro TA 9/1000. $\mathrm{O}$ valor obtido para se determinar a firmeza em grama força por centímetro quadrado $\left(\mathrm{gf} / \mathrm{cm}^{2}\right)$, é definido como a força máxima requerida para que uma parte do ponteiro penetre na polpa do produto.

O teor de carotenóides totais foi determinado utilizando-se o método descrito pelo AOAC (1990). As amostras foram congeladas em nitrogênio líquido $\left(-196^{\circ} \mathrm{C}\right)$. Todas as operações foram realizadas no escuro, para evitar a degradação dos carotenóides. Os resultados foram expressos em $\mu \mathrm{mol}$. $\mathrm{mL}^{-1}$.

A cor foi medida em colorímetro da marca Konica Minolta (Chroma meter, CR 400/410) e expressa pelo sistema de coordenadas retangulares $\mathrm{L}^{*} \mathrm{a} * \mathrm{~b} *$ conforme a CIE (Comission Internatinale d'Eclairage), onde $\mathrm{L}^{*}$ expressa em porcentagem valores de luminosidade $(0 \%=$ negro e $100 \%=$ branco), a* representa as intensidades de cores vermelha $(+)$ ou verde $(-)$ e b* as cores amarela $(+)$ ou azul (-). Foram realizadas três leituras em cada uma das três repetições em todos os tratamentos.

A atividade antioxidante (AA) das amostras foi medida através da desativação do radical DPPH. (1,1-difenil-2-picrilhidrazil) segundo Mensor et al. (2001). Para preparo da amostra foi utilizado a mistura de solventes etanol: água $(80: 20 \mathrm{v} / \mathrm{v})$ para a extração, por ser um bom solvente de extração para compostos fenólicos, apresentar facilidade de manipulação e baixa toxicidade. Os extratos das frutas foram obtidos em triplicata. Pesaram- se $3,0 \mathrm{~g}$ da polpa do fruto em tubos tipo Falcon onde foram adicionados $30 \mathrm{~mL}$ da mistura etanol: água $(80: 20 \mathrm{v} / \mathrm{v})$. Os tubos contendo a polpa do fruto e o solvente foram submetidos à trituração com Turrax por alguns minutos a temperatura ambiente. Em seguida, os extratos foram centrifugados a $5000 \mathrm{xg}$ durante 15 minutos. Na sequência os extratos foram filtrados e armazenados em frascos escuros e a temperatura de $8^{\circ} \mathrm{C}$, até o momento das análises, e por um período não superior a uma semana. $\mathrm{O}$ método se baseia no princípio de que o DPPH-, sendo um radical estável de coloração violeta, aceita um elétron ou um radical hidrogênio para tornar-se uma molécula estável, sendo reduzido na presença de um antioxidante e adquirindo coloração amarela. $\mathrm{Na}$ forma de radical, o DPPH possui uma absorção característica a $517 \mathrm{~nm}$, que desaparece à medida que ele vai sendo reduzido pelo hidrogênio doado por um composto antioxidante. A mistura de reação foi constituída pela adição de $500 \mu \mathrm{L}$ dos extratos etanólico da polpa, 3,0 mL de etanol $99 \%$ e $300 \mu \mathrm{L}$ do radical DPPH em solução de etanol $0,5 \mathrm{mM}$ e incubada por 45 minutos, em temperatura ambiente e ao abrigo da luz. A atividade antioxidante foi determinada pela equação: AA $(\%)=100-((\mathrm{Aa}-$ $\mathrm{Ab})$ x 100) / Ac, onde:Aa = absorbância da amostra; $\mathrm{Ab}=$ absorbância do branco; $\mathrm{Ac}=$ absorbância do controle negativo. $\mathrm{O}$ controle negativo foi feito substituindo-se o volume do extrato por igual volume do solvente utilizado na extração (etanol). O branco foi preparado substituindo o volume da solução de DPPH· por igual volume de solvente.

Os dados foram submetidos análise de variância no delineamento inteiramente ao acaso no esquema fatorial, seguida do teste de Tukey para comparação múltipla entre as médias. O nível de significância utilizado foi de $5 \%$.

\section{Resultados e Discussão}

A perda de massa das abóbora MP foi inferior a $0,2 \%$ até o nono dia de armazenamento. Após este período observou-se perda de massa mais acentuada para a abóbora MP de todos tratamentos, sendo o controle apresentou a maior perda neste momento $(0,5 \%)$. Esta perda após o nono dia de armazenamento demonstra que a partir deste ponto a conservação da abóbora MP embalada não é eficaz, ocorrendo perda na qualidade do produto. Apesar da perda de massa não ser significativa observa-se superioridade das embalagens com atmosfera modificada e vácuo em relação ao controle (Figura 1). 
Figura 1. Perda de massa (\%) para abóboras MP submetidas à atmosfera modificada.

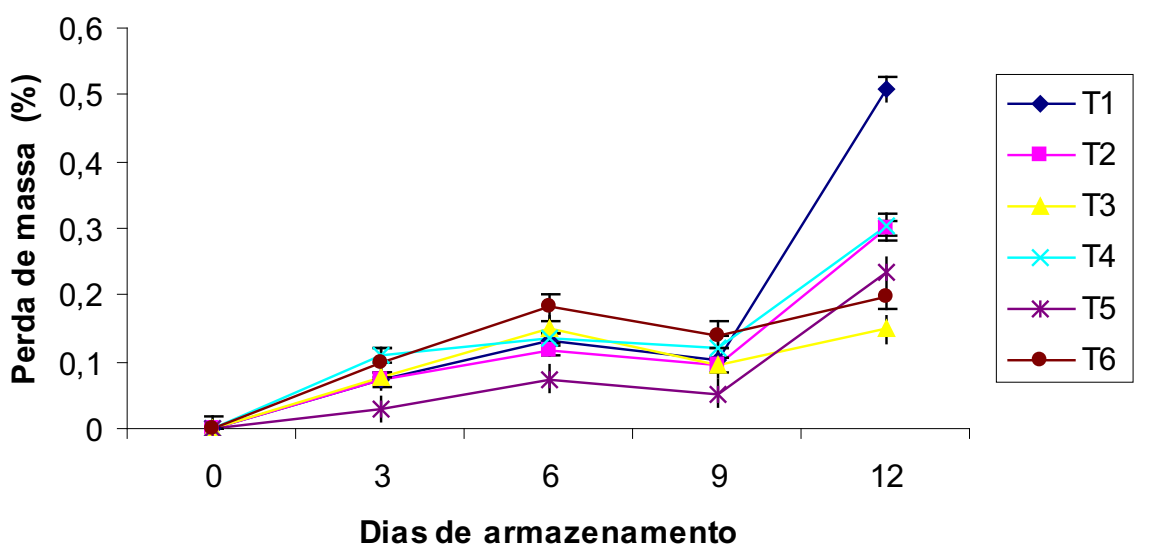

Legenda: T1- Controle, $\mathrm{T} 2-5 \%$ de $\mathrm{CO}_{2}$ e $4 \%$ de $\mathrm{O}_{2}$, T3- $6 \%$ de $\mathrm{CO}_{2}$ e $4 \%$ de $\mathrm{O}_{2}, \mathrm{~T} 4-7 \%$ de $\mathrm{CO}_{2}$ e $4 \%$ de $\mathrm{O}_{2}$, T5- $8 \%$ de $\mathrm{CO}_{2}$ e $4 \%$ de $\mathrm{O}_{2}$, T6- Vácuo

Fonte: Elaboração dos autores.

A perda de massa mais acentuada após o nono dia de armazenamento indica deterioração do produto armazenado. O tipo de corte das abóboras MP pode ter contribuído para os valores de perda de massa gradual durante o armazenamento, pois segundo Izumi et al. (1996) a perda de matéria fresca é o somatório da perda de água por transpiração e da perda de carbono através da respiração. Tal processo ocorre durante todo o período de armazenamento, sendo tanto maior quanto maior for a temperatura e quanto menor for o tamanho dos cortes.

Para os valores de AT (Tabela 1) de abóboras MP houve efeito de tratamento $(p<0,001)$ e dia $(\mathrm{p}<0,001)$. Para o $\mathrm{pH}$ (Tabela 2$)$ houve efeito da interação tratamentos e dias de armazenamento $(\mathrm{p}<0,0001)$.

Tabela 1. Acidez total ( $\mathrm{g}$ de ácido málico $100 \mathrm{~g}^{-1}$ ) de abóbora MP em atmosfera modificada ativa.

\begin{tabular}{|c|c|c|c|c|c|}
\hline \multicolumn{6}{|c|}{ Dias de armazenamento } \\
\hline Tratamentos & 0 & 3 & 9 & 12 & $\begin{array}{c}\text { Média geral dos } \\
\text { tratamentos }\end{array}$ \\
\hline T1- Controle & $0,52 \pm 0,11$ & $0,89 \pm 0,16$ & $1,26 \pm 0,41$ & $0,98 \pm 0,02$ & $1,05 \pm 0,27 \mathrm{~A}$ \\
\hline $\mathrm{T} 2-5 \%$ de $\mathrm{CO}_{2}$ e $4 \%$ de $\mathrm{O}_{2}$ & $0,52 \pm 0,11$ & $0,53 \pm 0,04$ & $1,28 \pm 0,18$ & $1,24 \pm 0,38$ & $1,02 \pm 0,42 \mathrm{~A}$ \\
\hline T3- $6 \%$ de $\mathrm{CO}_{2}$ e $4 \%$ de $\mathrm{O}_{2}{ }^{2}$ & $0,52 \pm 0,11$ & $0,47 \pm 0,06$ & $0,77 \pm 0,23$ & $0,66 \pm 0,05$ & $0,64 \pm 0,18 \mathrm{BC}$ \\
\hline T4- $7 \%$ de $\mathrm{CO}_{2}^{2}$ e $4 \%$ de $\mathrm{O}_{2}^{2}$ & $0,52 \pm 0,11$ & $0,51 \pm 0,12$ & $1,13 \pm 0,14$ & $0,70 \pm 0,23$ & $0,78 \pm 0,31 \mathrm{ABC}$ \\
\hline T5- $8 \%$ de $\mathrm{CO}_{2}$ e $4 \%$ de $\mathrm{O}_{2}$ & $0,52 \pm 0,11$ & $0,69 \pm 0,08$ & $0,92 \pm 0,12$ & $0,86 \pm 0,27$ & $0,82 \pm 0,18 \mathrm{ABC}$ \\
\hline T6- Vácuo & $0,52 \pm 0,11$ & $0,56 \pm 0,11$ & $0,93 \pm 0,12$ & $0,97 \pm 0,34$ & $0,82 \pm 0,27 \mathrm{AB}$ \\
\hline
\end{tabular}

Letras maiúsculas comparam médias gerais de tratamentos.

Fonte: Elaboração dos autores. 
Tabela 2. Potencial hidrogeniônico $(\mathrm{pH})$ de abóbora minimamente processada em atmosfera modificada ativa.

\begin{tabular}{|c|c|c|c|c|c|}
\hline \multicolumn{6}{|c|}{ Dias de armazenamento } \\
\hline Tratamentos & 0 & 3 & 9 & 12 & $\begin{array}{l}\text { Média geral dos } \\
\text { tratamentos }\end{array}$ \\
\hline T1- Controle & $6,3 \pm 0,2 \mathrm{aC}$ & $7,0 \pm 0,2 \mathrm{bAB}$ & $7,5 \pm 0,6 \mathrm{aA}$ & $6,4 \pm 0,1 \mathrm{cABC}$ & $7,0 \pm 0,6$ \\
\hline $\mathrm{T} 2-5 \%$ de $\mathrm{CO}_{2}$ e $4 \%$ de $\mathrm{O}_{2}$ & $6,3 \pm 0,2 \mathrm{aC}$ & $7,2 \pm 0,2 \mathrm{aA}$ & $7,2 \pm 0,2 \mathrm{aAB}$ & $6,0 \pm 0,2 \mathrm{bC}$ & $6,8 \pm 0,6$ \\
\hline T3- $6 \%$ de $\mathrm{CO}_{2}$ e $4 \%$ de $\mathrm{O}_{2}$ & $6,3 \pm 0,2 \mathrm{aC}$ & $6,9 \pm 0,1 \mathrm{aAB}$ & $7,0 \pm 0,1 \mathrm{aAB}$ & $6,8 \pm 0,1 \mathrm{aAB}$ & $6,9 \pm 0,1$ \\
\hline T4- $7 \%$ de $\mathrm{CO}_{2}$ e $4 \%$ de $\mathrm{O}_{2}$ & $6,3 \pm 0,2 \mathrm{aC}$ & $6,6 \pm 0,1 \mathrm{aBC}$ & $6,8 \pm 0,1 \mathrm{aB}$ & $6,9 \pm 0,5 \mathrm{aA}$ & $6,8 \pm 0,3$ \\
\hline T5- $8 \%$ de $\mathrm{CO}_{2}$ e $4 \%$ de $\mathrm{O}_{2}$ & $6,3 \pm 0,2 \mathrm{aC}$ & $6,6 \pm 0,0 \mathrm{abBC}$ & $6,9 \pm 0,2 \mathrm{aB}$ & $6,4 \pm 0,2 \mathrm{bABC}$ & $6,6 \pm 0,2$ \\
\hline T6- Vácuo & $6,3 \pm 0,2 \mathrm{aC}$ & $6,7 \pm 0,1 \mathrm{abABC}$ & $7,1 \pm 0,1 \mathrm{aAB}$ & $6,4 \pm 0,1 \mathrm{bABC}$ & $6,7 \pm 0,3$ \\
\hline Média geral dos dias & $6,3 \pm 0,2$ & $6,8 \pm 0,3$ & $7,0 \pm 0,4$ & $6,5 \pm 0,1$ & \\
\hline
\end{tabular}

Letras minúsculas comparam médias gerais de dias Letras maiúsculas comparam médias de tratamento Fonte: Elaboração dos autores.

O tempo de armazenamento influenciou significativamente o teor de AT, havendo aumento na sua concentração final. Os tratamentos 1 e 2 atingiram os maiores valores de acidez ao final do período avaliado, já os tratamentos 3 e 4 mostram os menores valores.

O acréscimo na AT que ocorreu de forma mais acentuada até o $9^{\circ}$ dia de armazenamento. Já os valores de $\mathrm{pH}$ (Tabela 2) aumentaram entre o 3 e $9^{\circ}$ dia de armazenamento diminuindo aos 12 dias de armazenamento, mas sendo valores superiores ao primeiro dia de avaliação. Segundo Teisson (1979), as variações no $\mathrm{pH}$ traduzem as variações na AT, assim para aumento dos valores de AT o comum é a redução nos valores de $\mathrm{pH}$, fato não constatado neste experimento. A AT aumentou principalmente nos dias 3 a 12 de armazenamento e o $\mathrm{pH}$ não diminuiu do terceiro ao nono dia de armazenamento. Silva et al. (2009) avaliando temperaturas de armazenamento e embalagens para abóbora (Curcubita moschata) minimamente processada, verificaram, em todos os tratamentos, que os valores de $\mathrm{pH}$ tenderam a se elevar após o nono dia de armazenamento. Os autores mencionam o fato que esse aumento no $\mathrm{pH}$ tem sido observado em diversos produtos minimamente processados. Entretanto, como esse efeito não é bem conhecido, acredita-se que essa elevação seja uma consequência dos efeitos do metabolismo normal de $\mathrm{CO}_{2}$ ou reação direta do tecido vegetal, eliminando o $\mathrm{CO}_{2}$ do interior de seus tecidos para os vacúolos ou ambiente e, assim, diminuindo a acidez causada por ele (KADER, 1986). A não redução dos valores de $\mathrm{pH}$ nas abóboras MP também é indicativo de que produto não sofreu nenhum tipo de fermentação em virtude uma possível contaminação microbiológica. O aumento da acidez titulável dos frutos ao longo do período de armazenamento também não se refere somente a possível contaminação da amostra, pode indicar uma possível síntese de ácidos orgânicos, assim como relatado por Fernandes et al. (2010) em mamão formosa armazenado em atmosfera modificada passiva. $\mathrm{O}$ aumento da acidez dos frutos pode se atribuído à formação do ácido galacturônico no processo de degradação da parede celular, processos que ocorrem durante o amadurecimento do mamão, enfatizam Costa e Balbino (2002). Fato semelhante pode ter ocorrido com as abóboras MP.

Para o teor de SS também ocorreu efeito de tratamento $(p<0,001)$ e dia $(p=0,002)$. Ocorreu aumento dos teores de SS com o armazenamento, no entanto este, foi em menor proporção nos tratamentos 3 e 4 das abóboras MP (Tabela 3). Sasaki et al. (2006) ao avaliar abóbora (Cucurbita moschata Duch) MP submetida a diferentes tipos de corte, observou que o tratamento em cubos não apresentou variações nos teores de sólidos solúveis, ficando em torno de $5,33{ }^{\circ}$ Brix. Já o corte em meia rodela apresentou um leve acréscimo nos teores de sólidos solúveis. 
Este discreto aumento pode estar associado à perda de água durante o armazenamento, o que é descrito por Chitarra e Chitarra (2005), que afirmam que os sólidos solúveis apresentam tendência de aumento com o amadurecimento devido ao aumento do teor de açúcares simples. De acordo com estes autores, os SS geralmente aumentam com o transcorrer do processo de amadurecimento do fruto, seja por biossíntese, pela degradação de polissacarídeos ou pela perda de água dos frutos resultando em maior concentração dos mesmos.

Tabela 3. Sólidos solúveis $\left({ }^{\circ}\right.$ Brix $)$ de abóbora minimamente processada em atmosfera modificada ativa.

\begin{tabular}{|c|c|c|c|c|c|}
\hline \multicolumn{6}{|c|}{ Dias de armazenamento } \\
\hline Tratamentos & 0 & 3 & 9 & 12 & $\begin{array}{c}\text { Média } \\
\text { geral dos } \\
\text { tratamentos }\end{array}$ \\
\hline T1- Controle & $6,6 \pm 0,7$ & $8,5 \pm 0,8$ & $7,5 \pm 0,5$ & $7,5 \pm 0,6$ & $7,9 \pm 0,8 \mathrm{~A}$ \\
\hline $\mathrm{T} 2-5 \%$ de $\mathrm{CO}_{2}$ e $4 \%$ de $\mathrm{O}_{2}$ & $6,6 \pm 0,7$ & $7,6 \pm 0,5$ & $7,5 \pm 0,2$ & $6,5 \pm 0,3$ & $7,2 \pm 0,6 \mathrm{ABC}$ \\
\hline T3- $6 \%$ de $\mathrm{CO}_{2}$ e $4 \%$ de $\mathrm{O}_{2}$ & $6,6 \pm 0,7$ & $6,9 \pm 0,6$ & $6,8 \pm 0,3$ & $5,7 \pm 0,7$ & $6,4 \pm 0,8 \mathrm{D}$ \\
\hline $\mathrm{T} 4-7 \%$ de $\mathrm{CO}_{2}$ e $4 \%$ de $\mathrm{O}_{2}$ & $6,6 \pm 0,7$ & $7,3 \pm 0,8 \mathrm{a}$ & $7,2 \pm 0,5 \mathrm{a}$ & $6,7 \pm 0,7 b$ & $7,5 \pm 0,4 \mathrm{AB}$ \\
\hline T5- $8 \%$ de $\mathrm{CO}_{2}$ e $4 \%$ de $\mathrm{O}_{2}$ & $6,6 \pm 0,7$ & $7,7 \pm 0,4$ & $7,4 \pm 0,6$ & $7,4 \pm 0,5$ & $6,6 \pm 0,2$ \\
\hline T6- Vácuo & $6,6 \pm 0,7$ & $7,2 \pm 0,3$ & $7,5 \pm 0,2$ & $6,8 \pm 0,3$ & $7,2 \pm 0,4 \mathrm{ABC}$ \\
\hline Média geral dos dias & $6,6 \mathrm{~b} \pm 0,7$ & $7,3 a \pm 0,8$ & $7,2 \mathrm{a} \pm 0,5$ & $6,7 \mathrm{~b} \pm 0,7$ & \\
\hline
\end{tabular}

Letras minúsculas comparam médias gerais de dias

Letras maiúsculas comparam médias gerais de tratamentos

Fonte: Elaboração dos autores.

Houve efeito de tratamento $(p=0,005)$ e dia 3 e 4 , que mostraram os maiores valores ao final $(\mathrm{p}<0,001)$ para os valores de ratio das abóboras MP do armazenamento. Como este índice representa (Tabela 4). Observou-se diminuição dos valores de ratio ao longo do período experimental. Esta redução ratio foi menos intensa nos tratamentos a relação SS/AT os resultados variam em função destes parâmetros, sendo assim os valores inferiores de AT para estes dois tratamentos justificam estes resultados.

Tabela 4. Ratio (SS/AT) de abóbora minimamente processada em atmosfera modificada ativa.

\begin{tabular}{|c|c|c|c|c|c|}
\hline \multicolumn{6}{|c|}{ Dias de armazenamento } \\
\hline Tratamentos & 0 & 3 & 9 & 12 & $\begin{array}{c}\text { Média } \\
\text { geral dos } \\
\text { tratamentos }\end{array}$ \\
\hline T1- Controle & $13,2 \pm 4,5$ & $9,8 \pm 2,4$ & $6,5 \pm 2,6$ & $7,7 \pm 0,7$ & $8,0 \pm 2,3 \mathrm{~B}$ \\
\hline $\mathrm{T} 2-5 \%$ de $\mathrm{CO}_{2}$ e $4 \%$ de $\mathrm{O}_{2}$ & $13,2 \pm 4,5$ & $14,4 \pm 1,2$ & $6,0 \pm 1,0$ & $5,6 \pm 2,0$ & $8,7 \pm 4,5 \mathrm{~B}$ \\
\hline T3- $6 \%$ de $\mathrm{CO}_{2}$ e $4 \%$ de $\mathrm{O}_{2}$ & $13,2 \pm 4,5$ & $14,7 \pm 2,9$ & $9,2 \pm 2,1$ & $8,6 \pm 01,6$ & $10,9 \pm 0,8 \mathrm{D}$ \\
\hline T4- $7 \%$ de $\mathrm{CO}_{2}$ e $4 \%$ de $\mathrm{O}_{2}$ & $13,2 \pm 4,5$ & $13,6 \pm 2,6$ & $6,2 \pm 0,9$ & $10,2 \pm 3,2$ & $10,0 \pm 03,9$ \\
\hline T5- $8 \%$ de $\mathrm{CO}_{2}$ e $4 \%$ de $\mathrm{O}_{2}$ & $13,2 \pm 4,5$ & $11,3 \pm 1,6$ & $8,3 \pm 1,7$ & $9,4 \pm 3,7$ & $9,7 \mathrm{AB} \pm 2,6$ \\
\hline T6- Vácuo & $13,2 \pm 4,5$ & $13,2 \pm 2,7$ & $8,1 \pm 1,2$ & $7,5 \pm 2,1$ & $9,6 \pm 3,2 \mathrm{AB}$ \\
\hline Média geral dos dias & $13,2 a \pm 3,9$ & $12,9 a \pm 2,8$ & $8,2 b \pm 3,1$ & $8,9 b \pm 3,3$ & \\
\hline
\end{tabular}

Fonte: Elaboração dos autores. 
Os tratamentos não influenciaram na firmeza das abóboras MP durante o período em estudo $(p=0,64)$. Também não houve efeito de dia $(p=0,33)$ e nem de interação deste com os tratamentos $(p=0,65)$, conforme apresenta a Tabela 5. A média geral dos tratamentos mostra que as concentrações de 6 e 7\% de $\mathrm{CO}_{2}$, mantiveram os maiores valores de firmeza durante o armazenamento.

Tabela 5. Firmeza $\left(\mathrm{gf} / \mathrm{cm}^{2}\right)$ de abóbora minimamente processada em atmosfera modificada ativa.

\begin{tabular}{|c|c|c|c|c|c|}
\hline \multicolumn{6}{|c|}{ Dias de armazenamento } \\
\hline Tratamentos & 0 & 3 & 9 & 12 & $\begin{array}{c}\text { Média } \\
\text { geral dos } \\
\text { tratamentos }\end{array}$ \\
\hline T1-Controle & $1002,5 \pm 11,1$ & $1010,3 \pm 9,8$ & $936,5 \pm 143,8$ & $837,7 \pm 197,3$ & $928,2 \pm 143,4$ \\
\hline $\mathrm{T} 2-5 \%$ de $\mathrm{CO}_{2}$ e $4 \%$ de $\mathrm{O}_{2}$ & $1002,5 \pm 11,1$ & $1016,7 \pm 4,9$ & $1013,3 \pm 7,8$ & $973,5 \pm 76,3$ & $1001,2 \pm 43,7$ \\
\hline $\mathrm{T} 3-6 \%$ de $\mathrm{CO}_{2}$ e $4 \%$ de $\mathrm{O}_{2}$ & $1002,5 \pm 11,1$ & $1016,8 \pm 14,1$ & $989,7 \pm 32,0$ & $973,3 \pm 76,5$ & $993,3 \pm 46,2$ \\
\hline T4- $7 \%$ de $\mathrm{CO}_{2}$ e $4 \%$ de $\mathrm{O}_{2}$ & $1002,5 \pm 11,1$ & $912,5 \pm 10,6$ & $955,8 \pm 106,4$ & $1018,0 \pm 3,0$ & $962,1 \pm 88,3$ \\
\hline T5- $8 \%$ de $\mathrm{CO}_{2}$ e $4 \%$ de $\mathrm{O}_{2}$ & $1002,5 \pm 11,1$ & $944,7 \pm 121,0$ & $947,8 \pm 69,1$ & $960,3 \pm 79,6$ & $950,9 \pm 80,5$ \\
\hline T6- Vácuo & $1002,5 \pm 11,1$ & $1016,0 \pm 3,0$ & $988,3 \pm 41,1$ & $814,7 \pm 355,6$ & $939,7 \pm 202,4$ \\
\hline Média geral dos dias & $1002,5 \pm 9,6$ & $988,5 \pm 65,3$ & $976,3 \pm 68,9$ & $940,0 \pm 155,5$ & \\
\hline
\end{tabular}

Fonte: Elaboração dos autores.

Alves et al. (2010) avaliaram o efeito do tempo de armazenamento sobre a qualidade de produto minimamente processado à base de hortaliças, abóbora (Cucurbita moschata Duch), cenoura (Daucus carota L.), chuchu (Sechium edule Swartz) e mandioquinha-salsa (Arracacia xanthorrhiza Bancroft) e constataram também que a firmeza não foi afetada significativamente pelo tempo de armazenamento em nenhuma das hortaliças minimamente processadas. A medição da firmeza da polpa dá uma idéia das transformações na estrutura celular, coesão das células e alterações bioquímicas, responsáveis pela textura do produto. Na realidade, a firmeza é apenas uma de um grupo de propriedades responsável pela textura dos produtos hortícolas (CHITARRA; CHITARRA, 2005).

Para o teor de carotenóides totais avaliado (Tabela 6) houve efeito da interação tratamento e dia de armazenamento $(p<0,001)$. O teor de carotenóides variou até o nono dia de armazenamento mantendo os valores iniciais ou aumentado, assim como para atividade antioxidante. Após este período observouse diminuição destes teores para todos tratamentos
Aos 12 dias, observou-se maior perda dos teores de carotenóides com o aumento da concentração de $\mathrm{CO}_{2}$ Os tratamentos de 7 e $8 \%$ de $\mathrm{CO}_{2}$ apresentaram maior teor de carotenóides que aquele com $6 \%$ de $\mathrm{CO}_{2}$ Os teores mais elevados de $\mathrm{CO}_{2}$ podem ter contribuído para redução do metabolismo das abóboras MP, reduzindo a degradação dos carotenóides.

De modo diferente, Sasaki et al. (2005) constataram que abóboras cortadas em retalhos tiveram uma redução drástica nos teores de carotenóides totais do dia do processamento (dia $0)$ para o $3^{\circ}$ dia de armazenamento. Após esse período, os valores tenderam a ficar estáveis até o final do período de armazenamento. Os autores mencionam que isso pode ter ocorrido devido a maior intensidade de injúria causada por teste tipo de corte que provocou maior exposição dos tecidos à luz e ao oxigênio, que são fatores que degradam os carotenóides segundo Klein, King e Grossman (1985).Além disso, esse tipo de corte provocou maior extravazamento do suco celular e, provavelmente uma maior perda dos carotenóides que ficam estocados nos cromoplastos. 
Tabela 6. Teor de carotenóides $\left(\mu \mathrm{mol} . \mathrm{mL}^{-1}\right)$ em abóbora minimamente processada em atmosfera modificada ativa.

\begin{tabular}{lcccc}
\hline \multicolumn{1}{c}{ Tratamentos } & 0 & 3 & 9 & 12 \\
\hline T1- Controle & $878,8 \pm 105,8 \mathrm{abA}$ & $737,1 \pm 278,9 \mathrm{bC}$ & $1681,6 \pm 425,5 \mathrm{aB}$ & $1202,8 \pm 125,5 \mathrm{abAB}$ \\
$\mathrm{T} 2-5 \%$ de $\mathrm{CO}_{2}$ e $4 \%$ de $\mathrm{O}_{2}$ & $878,8 \pm 105,8 \mathrm{aA}$ & $727,3 \pm 122,0 \mathrm{aC}$ & $1371,3 \pm 326,3 \mathrm{aB}$ & $1529,5 \pm 279,4 \mathrm{aA}$ \\
$\mathrm{T} 3-6 \%$ de $\mathrm{CO}_{2}$ e $4 \% \mathrm{de} \mathrm{O}_{2}$ & $878,8 \pm 105,8 \mathrm{bA}$ & $1170,8 \pm 253,6 \mathrm{bABC}$ & $2931,4 \pm 734,6 \mathrm{aA}$ & $346,2 \pm 71,5 \mathrm{bB}$ \\
$\mathrm{T} 4-7 \%$ de $\mathrm{CO}_{2}$ e $4 \%$ de $\mathrm{O}_{2}$ & $878,8 \pm 105,8 \mathrm{bcA}$ & $1797,2 \pm 322,1 \mathrm{aAB}$ & $1618,4 \pm 226,9 \mathrm{abB}$ & $499,4 \pm 44,5 \mathrm{cB}$ \\
T5- $8 \%$ de $\mathrm{CO}_{2}$ e $4 \%$ de $\mathrm{O}_{2}$ & $878,8 \pm 105,8 \mathrm{abA}$ & $953,9 \pm 248,6 \mathrm{abBC}$ & $1416,0 \pm 163,5 \mathrm{aB}$ & $377,1 \pm 74,6 \mathrm{bB}$ \\
T6- Vácuo & $878,8 \pm 105,8 \mathrm{bcA}$ & $1978,9 \pm 417,8 \mathrm{aA}$ & $1240,0 \pm 149,1 \mathrm{abB}$ & $369,5 \pm 77,9 \mathrm{cB}$ \\
\hline
\end{tabular}

Houve efeito da interação tratamento*dia $(\mathrm{p}<0,001)$

Letras minúsculas comparam médias de dia em cada tratamento

Letras maiúsculas comparam médias de tratamento em cada dia

Médias seguidas de pelo menos 1 letra em comum não diferem estatisticamente

Fonte: Elaboração dos autores.

Já em cenouras descascadas armazenada a $1^{\circ} \mathrm{C}$ e embalada em sacolas de plástico, os teores de $\alpha$ e $\beta$-caroteno decresceram continuamente durante o armazenamento, atingindo após 28 dias cerca de $33 \%$ do teor inicial (LI; BARTH, 1998). A retenção de carotenóides totais pode variar em função do filme plástico utilizado, como resultado do grau de modificação da atmosfera interna obtido para filmes de diferentes permeabilidades e espessuras. Carlin et al. (1990) relatam que em cenoura embalada em filme menos permeável a oxigênio não ocorreu alteração dos teores de carotenóides, enquanto no filme mais permeável a oxigênio houve redução de $25 \%$ do teor inicial, após 12 dias de armazenamento.
Para a luminosidade houve somente efeito de tratamento $(\mathrm{p}=0,012)$. Os tratamentos cinco e seis diferiram dos demais pelo maior e menor valor de luminosidade respectivamente, observada na média geral dos resultados (Tabela 7). No entanto, ao avaliar o $12^{\circ}$ dia de armazenamento notouse o maior valor de luminosidade obtido para o tratamento 4. Este tratamento também demonstrou neste momento teor elevado de carotenóides.

Para Sasaki et al. (2006) a luminosidade (L) das abóboras MP com corte em meia-rodela e cubos permaneceu inalterada durante os 12 dias armazenamento, fato também constatado neste experimento.

Tabela 7. Luminosidade (\%) de abóbora minimamente processada em atmosfera modificada ativa.

\begin{tabular}{|c|c|c|c|c|c|}
\hline \multicolumn{6}{|c|}{ Dias de armazenamento } \\
\hline Tratamentos & 0 & 3 & 9 & 12 & $\begin{array}{l}\text { Média geral dos } \\
\text { tratamentos }\end{array}$ \\
\hline T1- Controle & $61,6 \pm 0,4$ & $68,3 \pm 1,8$ & $71,6 \pm 2,5$ & $66,3 \pm 8,3$ & $68,8 \mathrm{~A} \pm 5,0$ \\
\hline $\mathrm{T} 2-5 \%$ de $\mathrm{CO}_{2}$ e $4 \%$ de $\mathrm{O}_{2}$ & $61,6 \pm 0,4$ & $70,3 \pm 1,8$ & $69,6 \pm 2,7$ & $64,9 \pm 6,9$ & $68,2 \mathrm{AB} \pm 4,6$ \\
\hline $\mathrm{T} 3-6 \%$ de $\mathrm{CO}_{2}$ e $4 \%$ de $\mathrm{O}_{2}$ & $61,6 \pm 0,4$ & $70,0 \pm 2,5$ & $70,8 \pm 5,1$ & $64,4 \pm 5,6$ & $68,4 \mathrm{AB} \pm 5,0$ \\
\hline T4- $7 \%$ de $\mathrm{CO}_{2}$ e $4 \%$ de $\mathrm{O}_{2}$ & $61,6 \pm 0,4$ & $67,6 \pm 2,5$ & $67,6 \pm 7,3$ & $71,1 \pm 5,6$ & $68,8 \mathrm{~A} \pm 5,1$ \\
\hline T5- $8 \%$ de $\mathrm{CO}_{2}$ e $4 \%$ de $\mathrm{O}_{2}$ & $61,6 \pm 0,4$ & $67,7 \pm 7,1$ & $74,6 \pm 2,3$ & $68,5 \pm 4,0$ & $70,2 \mathrm{~A} \pm 5,3$ \\
\hline T6- Vácuo & $61,6 \pm 0,4$ & $70,1 \pm 2,0$ & $69,6 \pm 5,4$ & $64,0 \pm 4,9$ & $67,9 \mathrm{AB} \pm 4,8$ \\
\hline Média geral dos dias & $61,6 \mathrm{~B} \pm 3,5$ & $67,9 \pm 4,2$ & $69,3 \pm 5,4$ & $65,8 \pm 5,7$ & \\
\hline
\end{tabular}

Letras maiúsculas comparam médias gerais de tratamentos.

Fonte: Elaboração dos autores 
Para o parâmetro de cor a* observou-se somente efeito de dia $(p=0,029)$, sem diferença entre os tratamentos. Ao longo do período experimental os valores de cor vermelha $\left(\mathrm{a}^{*}\right)$ diminuíram, indicando uma redução do componente de cor vermelho (Tabela 8). Alves et al. (2010) não encontraram variação no valor de cor vermelha $\left(\mathrm{a}^{*}\right)$ para abóbora MP, já para cenoura verificaram decréscimo nos valores deste componente de cor, sugerindo que o processo metabólico envolvido nesta mudança de cor pode ser a degradação dos carotenóides, que conferem pigmentação que variam do amarelo ao vermelho, sobretudo o beta-caroteno, que está relacionado com a pigmentação vermelhoalaranjada de cenouras. Este fato pode ter ocorrido para as abóboras MP deste experimento.

Tabela 8. Parâmetro de cor a* de abóbora minimamente processada em atmosfera modificada ativa.

\begin{tabular}{|c|c|c|c|c|c|}
\hline \multicolumn{6}{|c|}{ Dias de armazenamento } \\
\hline Tratamentos & 0 & 3 & 9 & 12 & $\begin{array}{l}\text { Média geral dos } \\
\text { tratamentos }\end{array}$ \\
\hline T1- Controle & $21,6 \pm 1,9$ & $20,6 \pm 2,3$ & $16,8 \pm 2,9$ & $18,3 \pm 8,7$ & $18,5 \pm 5,0$ \\
\hline $\mathrm{T} 2-5 \%$ de $\mathrm{CO}_{2}$ e $4 \%$ de $\mathrm{O}_{2}$ & $21,6 \pm 1,9$ & $19,0 \pm 3,6$ & $15,7 \pm 6,3$ & $17,6 \pm 2,8$ & $17,4 \pm 4,1$ \\
\hline $\mathrm{T} 3-6 \%$ de $\mathrm{CO}_{2}$ e $4 \%$ de $\mathrm{O}_{2}$ & $21,6 \pm 1,9$ & $17,9 \pm 2,7$ & $12,6 \pm 6,6$ & $16,0 \pm 4,5$ & $15,5 \pm 4,8$ \\
\hline $\mathrm{T} 4-7 \%$ de $\mathrm{CO}_{2}$ e $4 \%$ de $\mathrm{O}_{2}$ & $21,6 \pm 1,9$ & $21,4 \pm 2,6$ & $16,5 \pm 7,2$ & $16,5 \pm 9,2$ & $18,1 \pm 6,5$ \\
\hline T5- $8 \%$ de $\mathrm{CO}_{2}$ e $4 \%$ de $\mathrm{O}_{2}$ & $21,6 \pm 1,9$ & $19,8 \pm 7,4$ & $9,4 \pm 3,1$ & $15,9 \pm 1,6$ & $15,0 \pm 6,2$ \\
\hline T6- Vácuo & $21,6 \pm 1,9$ & $18,1 \pm 2,2$ & $16,6 \pm 7,3$ & $20,5 \pm 2,4$ & $18,4 \pm 4,4$ \\
\hline Média geral dos dias & $21,6 \pm 1,6$ & $19,8 \mathrm{a} \pm 3,4$ & $15,6 \mathrm{~b} \pm 5,8$ & $18,1 \mathrm{ab} \pm 5,0$ & \\
\hline
\end{tabular}

Letras minúsculas comparam médias gerais de dias.

Fonte: Elaboração dos autores.

Já para o parâmetro de cor b* (Tabela 9) os valores positivos indicam a presença do componente de cor amarelo. Estatisticamente houve somente efeito de tratamentos $(p=0,013)$, mas pode-se observar uma redução dos valores deste componente de cor ao longo dos dias de análise. Segundo Alves et al. (2010) essa redução indica que houve uma diminuição da coloração amarela desses produtos, a qual é frequente em produtos minimamente processados, em razão dos cortes sofridos, podendo ocorrer oxidação enzimática, por meio da interação entre substratos e enzimas e, também, por perdas de vitaminas, principalmente os carotenóides que conferem a coloração amarela-alaranjada.

Tabela 9. Parâmetro de cor $b^{*}$ de abóbora minimamente processada em atmosfera modificada ativa.

\begin{tabular}{cccccl}
\hline \multicolumn{5}{c}{ Dias de armazenamento } \\
\hline Tratamentos & 0 & 3 & 9 & 12 & $\begin{array}{c}\text { Média geral dos } \\
\text { tratamentos }\end{array}$ \\
\hline Controle & $62,0 \pm 6,6$ & $56,8 \pm 0,7$ & $49,9 \pm 2,6$ & $55,2 \pm 6,2 \pm 6,2$ & $54,0 \mathrm{AB} \pm 4,6$ \\
$5 \%$ de $\mathrm{CO}_{2}$ e $4 \%$ de $\mathrm{O}_{2}$ & $62,0 \pm 6,6$ & $54,1 \pm 4,5$ & $53,3 \pm 2,2$ & $53,8 \pm 3,9$ & $53,8 \mathrm{AB} \pm 3,2$ \\
$6 \%$ de $\mathrm{CO}_{2}$ e $4 \%$ de $\mathrm{O}_{2}$ & $62,0 \pm 6,6$ & $53,3 \pm 5,2$ & $53,4 \pm 9,1$ & $49,8 \pm 6,4$ & $52,2 \mathrm{~B} \pm 6,4$ \\
$7 \%$ de $\mathrm{CO}_{2}$ e $4 \%$ de $\mathrm{O}_{2}$ & $62,0 \pm 6,6$ & $55,8 \pm 2,7$ & $57,0 \pm 4,8$ & $51,4 \pm 11,3$ & $54,7 \mathrm{AB} \pm 6,8$ \\
$8 \%$ de $\mathrm{CO}_{2}$ e $4 \%$ de $\mathrm{O}_{2}$ & $62,0 \pm 6,6$ & $57,9 \pm 4,1$ & $45,8 \pm 3,1$ & $52,1 \pm 4,4$ & $51,9 \mathrm{~B} \pm 6,2$ \\
$\quad$ Vácuo & $62,0 \pm 6,6$ & $52,0 \pm 6,8$ & $54,5 \pm 6,7$ & $58,0 \pm 6,5$ & $54,8 \mathrm{AB} \pm 6,3$ \\
Média geral dos dias & $62,0 \mathrm{~A} \pm 5,7$ & $56,0 \pm 5,1$ & $53,7 \pm 6,7$ & $54,6 \pm 7,0$ & \\
\hline
\end{tabular}

Letras maiúsculas comparam médias gerais de tratamentos.

Fonte: Elaboração dos autores. 
A embalagem utilizada contribui para a manutenção da cor, ocorrendo pequena diferença entre as embalagens. Segundo Silva et al. (2009) a embalagem apresenta influência signifcativa na manutenção da cor, sendo que o PVC permite maior conservação dos atributos de qualidade da abóbora MP, com exceção da cor, que sofreu menores alterações quando usada embalagem a vácuo.

Para os dados de atividade antioxidante medida através da desativação do radical DPPH houve efeito da interação $(\mathrm{p}<0,0001)$ tratamento e dia de armazenamento. A atividade antioxidante diminuiu durante o armazenamento. Observou-se após o primeiro dia de análise aumento dos valores de atividade antioxidante com posterior redução, após o nono dia de armazenamento (Tabela 10). A média geral dos tratamentos mostra menor atividade antioxidante para os pedaços de abóbora embalados a vácuo.

Tabela 10. Atividade antioxidante por DPPH (\%) em abóbora minimamente processada em atmosfera modificada ativa.

\begin{tabular}{|c|c|c|c|c|c|}
\hline \multicolumn{6}{|c|}{ Dias de armazenamento } \\
\hline Tratamentos & 0 & 3 & 9 & 12 & $\begin{array}{c}\text { Média } \\
\text { geral dos } \\
\text { tratamentos }\end{array}$ \\
\hline T1- Controle & $56,1 \pm 3,5 \mathrm{aA}$ & $58,4 \pm 1,5 \mathrm{aA}$ & $58,4 \pm 2,1 \mathrm{aA}$ & $47,5 \pm 1,0 \mathrm{bB}$ & $54,8 \pm 5,6$ \\
\hline $\mathrm{T} 2-5 \%$ de $\mathrm{CO}_{2}$ e $4 \%$ de $\mathrm{O}_{2}$ & $56,1 \pm 3,5 \mathrm{aA}$ & $59,0 \pm 7,0 \mathrm{aA}$ & $57,6 \pm 1,0 \mathrm{aA}$ & $41,8 \pm 1,0 \mathrm{bBCD}$ & $52,8 \pm 7,7$ \\
\hline T3- $6 \%$ de $\mathrm{CO}_{2}$ e $4 \%$ de $\mathrm{O}_{2}$ & $56,1 \pm 3,5 \mathrm{aA}$ & $58,7 \pm 3,6 \mathrm{aA}$ & $58,9 \pm 3,7 \mathrm{aA}$ & $44,4 \pm 2,2 \mathrm{bBC}$ & $54,0 \pm 7,7$ \\
\hline T4- $7 \%$ de $\mathrm{CO}_{2}$ e $4 \%$ de $\mathrm{O}_{2}$ & $56,1 \pm 3,5 \mathrm{aA}$ & $62,1 \pm 2,7 \mathrm{aA}$ & $56,7 \pm 1,5 \mathrm{aA}$ & $35,8 \pm 1,9 \mathrm{bDE}$ & $53,0 \pm 12,1$ \\
\hline T5- $8 \%$ de $\mathrm{CO}_{2}$ e $4 \%$ de $\mathrm{O}_{2}$ & $56,1 \pm 3,5 \mathrm{aA}$ & $56,3 \pm 0,9 \mathrm{aA}$ & $57,5 \pm 0,7 \mathrm{aA}$ & $37,9 \pm 3,0 \mathrm{bCDE}$ & $50,6 \pm 9,7$ \\
\hline T6- Vácuo & $56,1 \pm 3,5 \mathrm{aA}$ & $58,7 \pm 2,8 \mathrm{aA}$ & $45,0 \pm 1,2 \mathrm{bB}$ & $34,5 \pm 1,8 \mathrm{cE}$ & $46,0 \pm 10,7$ \\
\hline Média geral dos dias & $56,1 \pm 3,0$ & $58,5 \pm 3,6$ & $55,7 \pm 5,1$ & $42,9 \pm 7,4$ & \\
\hline
\end{tabular}

Letras minúsculas comparam médias de dias em cada tratamento Letras maiúsculas comparam médias de tratamento em cada dia Fonte: Elaboração dos autores.

Braga et al. (2010) ao avaliar a atividade antioxidante em abricó observaram reduzida atividade antioxidante, baixo teor de polifenóis e flavonóis totais, apesar deste fruto se destacar como fonte de pró vitamina A ( carotenóides). Estes autores avaliaram a atividade antioxidante pelos métodos Oxygen Radical Absorbance Capacity (ORAC) e Trolox Equivalent Antioxidant Capacity (TEAC). Na presente pesquisa, pela metodologia utilizada para determinação da atividade antioxidante foi observada uma redução da porcentagem de atividade antioxidante após o $9^{\circ}$ dia de armazenamento, ou seja, a mesma tendência observada para o teor de carotenóides totais.

\section{Conclusões}

O produto minimamente processado de abóbora pode ser conservar sua qualidade até o nono dia de avaliação. As atmosferas de 6 e $7 \%$ de $\mathrm{CO}_{2}$ e $4 \%$ de $\mathrm{O}_{2}$ são as mais indicadas para o armazenamento à temperatura de $5{ }^{\circ} \mathrm{C}$, para os valores de perda de massa, AT e teores de carotenóides.

\section{Referências}

ALVES, J. A.; VILAS BOAS, E. V. B.; SOUZA, E. C.; VILAS BOAS, B. M.; PICCOLI, R. H. Vida útil de produto minimamente processado composto por abóbora, cenoura, chuchu e mandioquinha-salsa. Ciência 
e Agrotecnologia, Lavras, v. 34, n. 1, p. 182-189, jan./ fev. 2010.

ASSOCIATION OF OFFICIAL ANALYTICAL CHEMISTS - AOAC. Official methods of analysis. Washington D.C, 1990. p. 1048.

BARRY-RYAN, C.; O'BEIRNE, D. Effects of peeling methods on the quality of ready-to-use carrot slices. International Journal of Food Science and Technology, Oxford, v. 35, n. 2, p. 243-254, 2000.

BRAGA, A. C. C.; SILVA, A. E.; PELAIS, A. C.; BICHARA, C. M. G.; POMPEU, D. R. Atividade antioxidante e quantificação de compostos bioativos dos frutos de abricó (Mammea Americana). Revista Alimentos e Nutrição, Araraquara, v. 21, n. 1, p. 31-36, 2010.

BRECHT, J. K. Physiology of lightly processed fruits andvegetables. HortScience, Alexandria, v. 30, n. 1, p. 18-22, 1995.

CAMARGO FILHO, W. P.; MAZZEI, A. R.; ALVES, H. S. Mercado de abóboras nas cidades de São Paulo e Buenos Aires: oportunidades de expansão. Informações Econômicas, São Paulo, v. 33, n. 9, p. 61-65, 2003.

CARLIN, F.; NUGYEN-THE, C.; HILBERT, G.; CHAMBROY, Y. Modified atmosphere packaging of fresh "ready-to-use" grated carrots in polymeric films. Journal of Food Science, Chicago, v. 55, n. 4, p. 10331038, 1990.

CHITARRA, M. I. F.; CHITARRA, A. B. Pós-colheita de frutas e hortaliças: fisiologia e manuseio. 2. ed. Lavras: UFLA, 2005. $785 \mathrm{p}$.

CISNERO-ZEVALLOS, L.; KROCHTA, J. M. Internal modified atmosphere of coated freshfruit and vegetables: Understanding relative humidity effects. Journal of Food Science, Chicago, v. 67, n. 8, p. 2792-2797, 2002.

COSTA, A. F. S.; BALBINO, J. M. S. Características da fruta para exportação e normas de qualidade. In: FOLEGATTI, M. I. S.; MATSUURA, F. C. A. U. (Ed.). Mamão: pós-colheita. Brasília, DF: Embrapa Informação Tecnológica, 2002. p. 12-18. (Série Frutas do Brasil, 21).

DAMODARAN, S.; PARKIN, K.; FENNEMA, O. R. Fennema's food chemistry. 4. ed. Boca Raton: CRC Press, 2008. 1144 p.

DURIGAN, J. F.; CASSARO, K. P. Hortaliças minimamente processadas. Horticultura Brasileira, Brasília, v. 18, p. 159-161, 2000. Suplemento.

FERNANDES, P. L. O.; AROUCHA, E. M. M.; SOUZA, P. A.; SOUSA, A. E. D.; FERNANDES, P. L. de O. Qualidade de mamão 'Formosa' produzido no RN e armazenado sob atmosfera passive. Revista Ciência Agronômica, Fortaleza, v. 41, n. 4, p. 599-604, 2010.

GERMAN, J. B.; DILLARD, C. J. Phytochemicals and targets of chronic disease. In: BILLACK, W. R.; OMAYE, S. T.; MESKIN, M. S.; JAHNER, D. (Ed.). Phytochemicals - a new paradigm. Pennssylvania: Technomic Publishing Company Inc, 1998.

INSTITUTO ADOLFO LUTZ - IAL. Métodos físicoquímicos para análise de alimentos. 4. ed. Coordenadores Odair Zenebon, Neus Sadocco Pascuet e Paulo Tiglea. São Paulo: Instituto Adolfo Lutz, 2008, p. 1020.

IZUMI, H.; WATADA, A. E.; KO, N. P.; DOUGLAS, W. Controlled atmosphere storage of carrots slices, sticks and shreds. Postharvest Biology and Technology, Amsterdam, v. 9, n. 2, p. 165-172, 1996.

KADER, A. A. Biochemical and physiological basis for efects of controlled and modifed atmospheres on fruits and vegetables. Food Technology, Chicago, v. 40, n. 5, p. 99-104, 1986.

KLEIN, B. P.; KING, D.; GROSSMAN, S. Cooxidation reations of lipoxygenase in plantsystems. Advanced in Free Radical Biology and Medicine, New York, v. 1, n. 1, p. 309-343, 1985

KLUGE, R. A.; COSTA, C. A.; VITTI, M. C. D.; ONGARELLI., M. das G.; JACOMINO, A .P.; MORETTI, C. L. Armazenamento refrigerado de beterraba minimamente processada em diferentes tipos de corte. Ciência Rural, Santa Maria, v. 36, n. 1, p. $263-$ 270, 2006.

LI, P.; BARHT, M. M. Impact of edible coatingson nutritional and physiological changes inlightlyprocessed carrots. Postharvest Biology and Technology, Amsterdam, v. 14, n. 1, p. 51-60, 1998.

LUENGO, R. F. A.; PARMAGNANI, R. M.; PARENTE, M. R.; LIMA, M. F. B. F. Tabela de composição nutricional das hortaliças. Brasília: EMBRAPA Hortaliças. 2000. 4 p.

MENSOR, L. L.; MENEZES, F. S.; LEITÃO, G. G.; REIS, A. S.; DOS SANTOS, T. C.; COUBE, C. S.; LEITÃO, S. G. Screening of brazilian plant extracts for antioxidant activity by the use of dpph free radical method, Phytotherapy Research, London, v. 15, n. 2, p. 127-130, 2001.

PODSEDEK, A. Natural antixidants and antioxidant capacity ob Brassica vegetables: A review. LWT-Food Science and Technology, London, v. 40, n. 1, p. 1-11, 2007. 
RAI, D. R.; OBEROI, H. S.; BABOO, B. RAI, D. R. Modified atmosphere packaging and its effect on quality and shelf-life of fruits and vegetables - an overview. Journal of Food Science and Technology, Mysore, v. 39, n. 3, p. 199-207, 2002.

SASAKI, F. F.; DEL AGUILA, J. S.; GALLO, C. R.; ORTEGA, E. M. M.; JACOMINO, A. P.; KLUGE R A. Alterações fisiológicas, qualitativas e microbiológicas durante o armazenamento de abóbora minimamente processada em diferentes tipos de corte. Horticultura Brasileira, Brasília, v. 24, n. 2, p. 170-174, 2006.

SILVA, A. V. C.; OLIVEIRA, D. S. N.; YAGUIU, P.; CARNELOSSI, M. A. G.; MUNIZ, E. N.; NARAIN, N. Temperatura e embalagem para abóbora minimamente processada. Ciência e Tecnologia de Alimentos, Campinas, v. 29, n. 2, p. 391-394, 2009.

SILVA, M. L.; COSTA, R. S.; SANTANA, A. S.; KOBLITZ, M. G. Compostos fenólicos, carotenódes e atividade antioxidante em produtos vegetais. Semina: Ciências Agrárias, Londrina, v. 31, n. 3, p. 669-682, 2010.

TEISSON, C. Le brunissement interne de Ananas. Fruits, Paris, v. 34, n. 4, p. 245-161, 1979.

TRESSLER, D. K.; JOSLYN, M. A. Fruits and vegetables juice processing technogy. Westport: Conn. Avi. 1961, 1028 p. 
